\title{
ACARA PERAGAAN BUSANA "TRUCE: THE TRUE ELUCIDATION OF CYBERBULLYING"
}

\author{
Veby Sabrina Firdaus ${ }^{1)}$, Ratih Marini ${ }^{2)}$ \\ ${ }^{1)}$ Sekolah Tinggi Ilmu Komunikasi London School of Public Relations Jakarta \\ ${ }^{2)}$ Sekolah Tinggi Ilmu Komunikasi London School of Public Relations Jakarta \\ Email: ${ }^{1)}$ vebysabrinafirdaus@ gmail.com, ${ }^{2}$ ratihmarini.10121996@gmail.com
}

\begin{abstract}
One of the problems which has been happening very often lately is the misuse of the internet mostly done by teenagers in Indonesia on social media, where social media is often used as a tool of cyberbullying. This fact is the main reason why the creators made an event that is also a campaign to spread awareness and invitation to not do cyberbullying with the social media influencers and teenagers as our main target audience. The event was a fashion show mixed with theatre acting and hip hop music. The main theme shown for this fashion show is Street Style with a touch of hip hop music because lately, hip hop is one of the popular music genres among society, especially the young people. Hip hop is considered to be a popular genre because it is known for its critical lyrics with deep meanings. The creators use theories such as Event Management Theory, Fashion Show Theory, Music Theory, Theatrical Theory, Social Criticism Theory, Social Message Theory, Cyberbullying Theory and Social Media Theory. The main theories that are used are Campaign Theory and K. Berlo's Communication Theory. The metode that is used is event management. The creators held this event entitled "TRUCE" which means The True Elucidation of Cyberbullying. The creators hope that this event will have an effect in the eyes of the general public and prevent themselves to not do cyberbullying.
\end{abstract}

Keywords : social media, cyberbullying, event, campaign, fashion show.

\section{PENDAHULUAN}

Berdasarkan artikel "Media Baru dan Karakteristiknya" (Aranditio, 2015) Dengan adanya internet, masyarakat lebih mudah untuk menyampaikan dan mendapatkan informasi, tetapi tidak sedikit dampak negatif yang didapatkan dari internet. Penyebab utamanya adalah karena internet dapat dibuka oleh masyarakat pada semua umur. UNICEF, bersama dengan Kementerian Komunikasi dan Informasi, The Berkman Center for Internet and Society, dan HarvardUniversity, melakukan survei nasional mengenai penggunaan dan tingkah laku penggunaan internet oleh para remaja di Indonesia. Survei ini memperlihatkan bahwa ada setidaknya 30 juta orang remaja di Indonesia yang mengakses internet. Studi ini menanyakan 400 responden dengan kisaran umur 10 sampai 19 tahun di seluruh Indonesia (Lukman, 2014).

Salah satu masalah yang sering terjadi di internet pada jaman modern ini adalah penyalahgunaan internet dalam media sosial. Dimana media sosial itu sendiri sering dijadikan sebagai tempat cyberbullying. Hal ini didukung oleh hasil survei global yang 
diadakan oleh Latitude News, Indonesia merupakan salah satu negara yang memiliki kasus cyberbullying tertinggi kedua di dunia setelah Jepang. Berdasarkan penelitian, 91\% responden asal Indonesia mengaku telah melihat kasus cyberbullying. Kemudian, data menunjukkan bahwa kasus cyberbullying di Indonesia sering terjadi melalui media sosial. (Kompasiana, 2014)

Salah satu contoh kasus cyberbullying yang sudah terjadi di media sosial Twitter adalah kasus yang dialami oleh Yoga Cahyadi. Pada Sabtu, 26 Mei 2013, pria asal Yogyakarta ini melakukan tindakan nekat dengan menabrakkan diri ke kereta api yang tengah melintas. Diduga kuat Yoga yang akrab dipanggil Kebo, memilih mengakhiri hidupnya karena tekanan dan hujatan akibat gagalnya acara hiburan Lockstock Fest\#2. Sebagai ketua penyelenggara, ia dianggap orang yang paling bertanggung jawab atas kegagalan acara tersebut. Sesaat sebelum memutuskan untuk bunuh diri, Yoga sempat berkicau di Twitter pribadinya

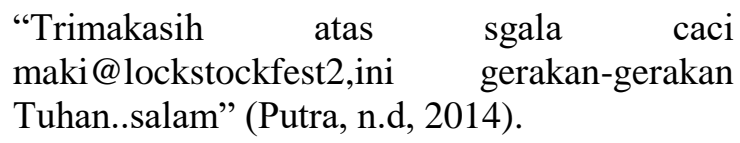

Sehingga dapat disimpulkan, bahwa cyberbullying yang dilakukan di media sosial dapat berdampak buruk, bahkan berakibat fatal terhadap korban.
Berdasarkan hasil survey yang dilakukan UNICEF, Harvard University, dan Kementerian Komunikasi dan Informatika, anak muda yang menjadi pengguna aktif media sosial di Indonesia mencapai angka 30 juta. 98 persen anak-anak muda di Indonesia mengerti apa itu sosial media, sementara 79,5 persen di antaranya adalah pengguna aktif. Hingga saat ini, Facebook, Twitter, Whatsapp, Path, dan Instagram masih menjadi platform media sosial yang banyak digandrungi anak-anak muda. (Mamduh, 2015)

Dari pernyataan diatas dapat disimpulkan bahwa kebanyakan pengguna media sosial adalah remaja atau biasa disebut dengan generasi millenial. Sedangkan menurut Qomariyah dalam jurnal yang berjudul Cyberbullying dalam media sosial, menjelaskan bahwa remaja sebagai salah satu pengguna internet masih belum mampu memilih aktivitas internet yang bermanfaat, para remaja juga cenderung mudah terpengaruh oleh lingkungan sosial mereka tanpa mempertimbangkan terlebih dulu efek positif atau negatif yang akan diterima saat melakukan aktivitas internet tertentu. (Akbar, n.d, h.2)

Berdasarkan data yang diperoleh UNICEF pada 2016, sebanyak 41 hingga 50 persen remaja di Indonesia dalam rentang usia 13 sampai 15 tahun pernah mengalami 
tindakan cyberbullying 2016. Beberapa tindakan di antaranya adalah doxing (mempublikasikan data personal orang lain), cyber stalking (penguntitan di dunia maya yang berujung pada penguntitan di dunia nyata), revenge pom (penyebaran foto atau video dengan tujuan balas dendam yang dibarengi dengan tindakan intimidasi dan pemerasan) dan beberapa tindakan cyberbullying lainnya. Salah satu contohnya adalah perilaku cyberbullying yang dilakukan kepada DPR mengunakan media sosial Instagram. (Kumparanstyle, 2017).

Berdasarkan latar belakang di atas dan fenomena-fenomena yang terjadi, dapat disimpulkan bahwa banyak remaja sekarang ini yang menyalahgunakan media sosial sebagai tempat cyberbullying dikarenakan para remaja memiliki sifat yang masih tidak stabil dan kurangnya sifat menghargai orang lain, serta penggunaan internet yang tidak di saring.

Dalam hal tersebut, ,enyelenggarakan sebuah kampanye untuk memberikan pesan kepada masyarakat adalah hal yang tepat untuk dilakukan. Kegiatan kampanye dapat dilakukan dalam berbagai bentuk, salah satunya adalah dengan menyelenggarakan sebuah event. Dikarenakan sebuah event merupakan salah satu media komunikasi secara nyata. Oleh karena itu, membuat sebuah acara kampanye dengan cara menyelenggarakan acara fashion show "street style" dengan sentuhan teatrikal dan musik adalah acara yang tepat untuk memberikan pesan kepada masyarakat, khususnya pada para remaja agar tidak melakukan cyberbullying. Bentuk theatrical yang akan dibawakan dalam acara ini adalah teatrikal tanpa dialog yang hanya menggunakan gerakan tubuh dan ekspresi dari para model. Acara ini akan memberikan awareness terhadap para remaja bahwa media sosial tidak harus dijadikan sarana untuk melakukan halhal yang negatif, khususnya untuk di jadikan sebagai media melakukan cyberbullying.

Alasan pembuat karya memilih untuk membuat sebuah acara fashion show diikuti dengan pernyataan dari Miuccia Prada "what you wear represents you to the world, especially now, when communication between is so fast, fashion is universal language that everyone understands." (Eaten, 2014). Dapat disimpulkan bahwa fashion adalah salah satu cara untuk Berkomunikasi. Adanya sentuhan teater dan musik dalam fashion show ini, di harapkan akan membuat para penonton lebih dapat mendalami pesan yang akan disampaikan. Dimana para penonton mendapatkan pesan tidak hanya lewat busana saja tetapi juga lewat teater dan musik.

Pembuat karya memilih tema "street style", dikarenakan pada sekarang ini street style sedang sangat diminati oleh masyarakat, 
khususnya para remaja di Indonesia. Salah satu penyebab street style banyak diminati karena street style adalah sebuah mode fashion yang simple, dimana semua orang dapat menggunakan di kehidupan sehari-hari sesuai dengan jati diri mereka sendiri, dengan tidak memberikan kesan berlebihan tetapi tetap memberikan nilai stylish. Street style dapat membuat orang tetap fashionable, tanpa harus membuat orang menjadi korban fashion. Dimana orang tidak perlu mengeluarkan uang banyak untuk tampil menjadi seseorang yang fashionable. (Wood, 2016). Dapat disimpulkan, bahwa fashion street style adalah sebuah mode busana yang simpel, sederhana dan banyak diminati orang, tetapi tetap memberi makna atau pesan dari jati diri orang yang memakainya.

Dr. Michael W. Waters, seseorang yang dikenal sebagai sosial aktifitis, motivational speaker, penceramah dan guru dalam kunjungannya ke World Association for Christian Communication (WACC), mengatakan bahwa, "Hip Hop music began in 1973 in New York's South Bronx, a place where an urban community lived in what appeared to be a war zone. People were living in hopelessness and their voices were not being heard. They find their voice in hip-hop, in the beat, in the music, in the community. Hip-hop becomes the cauldron out of which the voices of the people arise." (Staff, WACC,
2014). Sehingga dapat diartikan bahwa musik HipHop adalah salah satu genre musik yang dapat dijadikan sebagi media komunikasi dalam menyampaikan pesan dan curahan hati seseorang. Oleh karena itu, pembuat karya memilih musik bergenre HipHop karena dapat memudahkan acara dalam menyampaikan pesan dengan lirik yang ada di dalam lagu tersebut.

Berdasarkan latar belakang diatas, tujuan perencanaan ini adalah membuat konsep kritik sosial dalam bentuk fashion show "street style" dan hip hop, serta mengimplementasikan konsep kritik sosial dalam bentuk fashionshow "street style" dan HipHop. Masalah perencanaan dari acara ini adalah Bagaimana menyampaikan pesan kritik sosial yang terjadi di sosial media dengan menggunakan media acara Musik dan Fashion Show "Street Style".

Karya yang akan dibuat diharapkan dapat mendatangkan manfaat baik dari segi akademis maupun praktis. Dari karya atau acara ini, diharapkan dapat di jadikan sebagai saran atau masukan untuk orang-orang yang ingin membuat acara kampanye serupa.

Acara ini diadakan bertujuan untuk menyampaikan pesan kepada audience agar mengetahui tentang sebab dan dampak dari perilaku cyberbullying, dimana pesan acara ini diharapkan dapat menjadi sebuah masukan yang membangun dan diperhatikan oleh 
audience, khususnya para remaja pengguna internet untuk tidak melakukan cyberbullying dan menggunakan internet dengan baik dan benar.

\section{TINJAUAN PUSTAKA}

\subsection{Teori Kampanye}

Dalam beberapa kegiatan, terdapat jenis-jenis kampanye yang dilaksanakan secara prinsip untuk memotivasi atau membujuk dan mencapai tujuan tertentu. Maka Charles U. Larson dalam bukunya yang berjudul Persuasion, Reception and Responbility (California. Wardsworth Publishing Co. 1992) telah membagi jenisjenis kampanye sebagai berikut :

\section{Product-Orianted Campaigns}

Sebuah kegiatan kampanye yang berorientasi pada produk, dan biasanya dilakukan dalam kegiatan kampanye komersial promosi pemasaran suatu peluncuran produk baru.

2. Candidate-Oriented Campaigns Sebuah kegiatan kampanye yang berorientasi bagi calon (kandidat) untuk kepentingan kampanye politik (political campaign)

3. Ideological or Cause - Oriented Campaigns

Sebuah kegiatan kampaye yang berorientasi dan bertujuan bersifat khusus dan berdimensi perubahan sosial (sosial change campaign)

Berdasarkan jenis dan tujuannya, acara yang akan dibuat oleh pembuat karya termasuk ke dalam jenis kampanye Ideological or Cause - Oriented Campaigns. Karena acara yang akan dibuat dengan bertujuan khusus dan merubah perilaku sosial seseorang. Dimana acara ini dibuat memilki tujuan untuk mengajak masyarakat pengguna media sosial terutama remaja untuk menggunakan media sosial dengan bijak dan tidak melakukan cyberbulling. (Ruslan, 2008, h. 25-26)

\subsection{Cyberbullying}

Menurut Kowalski (2008) dalam bukunya berjudul Cyberbullying: Bullying in the Digital Age, definisi cyberbullying (meliputi penyalahgunaan teknologi komunikasi menyangkut apa, kepada siapa dilakukan, dan bagaimana dampaknya) terbukti sulit terkait dengan metode cyberbullying yang beragam. Beberapa kalangan menamakan bullying di internet dengan sebutan bullying elektronik, online social cruelty (kekejaman di dunia maya), emotional wilding (Kowalski, Limber, \&amp; Agatston, 2008).

Musik adalah proses komunikasi yang paling universal. Dengan musik, orang-orang dapat berkomunikasi dengan hanya 
mendengarkan lagu- lagu yang mereka dengar. Aserani Kurdi mengatakan bahwa musik adalah bagian dari seni yang menggunakan bunyi sebagai media penciptaannya. (2011, h.1). Pada generasi sekarang, banyak orangorang di Indonesia dan juga negara-negara lain di dunia yang menjadi penikmat musik. Salah satu genre musik yang sedang ramai digemari oleh generasi muda Indonesia, khususnya Jakarta, adalah musik yang bergenre hip hop. Hip hop bermakna seluruh kultur gerakan. Ketika berbicara soal rap, maka rap adalah bagian dari kultur hip-hop. Rap adalah $M C$ ing. DJ-ing adalah bagian dari kultur hip-hop. Breakdancing, b-boys, b-girls, caramu bertindak, berjalan, berpenampilan, dan berbicara semuanya adalah bagian dari kultur hip-hop. Musik hip-hop dibuat dari musik orang-orang kulit hitam, coklat, kuning, merah, putih. Musiknya dibuat dari musik apa pun yang memberimu semangat. (Bambaataa, 2005).

Pada generasi sekarang, banyak orang yang berpendapat bahwa musik hip hop dapat memberikan dampak yang negatif karena kata-kata dan cara penyampaiannya yang kasar, tetapi banyak yang tidak mengetahui bahwa dibalik lagu-lagu hip hop yang mengandung pesan yang sangat kritis dan tidak selalu negatif. Musik hip hop banyak di minati oleh pendengar musik dikarenakan memiliki ciri khas yang di kenal dengan bebas untuk menyampaikan pesan dan bebas untuk berpendapat, semua orang dapat memainkan dan mendengarkan musik hip hop tanpa adanya batasan. Musik hip hop juga dikenal keterikatannya dengan style atau fashion mode yang santai namun menarik. Style ini biasa dikenal dengan nama street style.

Street Style adalah gaya berpakaian yang sedang ramai diikuti dan menjadi tren oleh generasi muda. "Street style atau street fashion ini adalah gaya yang dapat ditemukan di jalanan di kota-kota besar yang juga pengekspresian diri dari generasi muda dengan khas kehidupan urban, dan bisa didapatkan hanya dari pakaian untuk kegiatan sehari-hari.\&quot; (Sasyachi, 2014.)

Menurut Umberto Eco, pakaian merupakan alat semiotika, mesin komunikasi. Fashion merupakan fenomena kultural, dalam artian fashion merupakan cara yang digunakan suatu kelompok atau individu untuk mengkomunikasikan identitasnya dan orang cenderung membuat penilaian berdasarkan atas apa yang dipakai oleh orang lain. fashion dianggap memiliki fungsi komunikatif dan termasuk suatu bentuk komunikasi artifaktual. Dimana artifaktual didefiniskan sebagai komunikasi yang berlangsung melalui pakaian. Pakaian bisa berfungsi sebagai bentuk komunikasi, dimana pakaian bisa menyampaikan pesan yang bersifat nonverbal. (Barnard, 1995). Hal itu dapat 
diartikan bahwa street style adalah suatu fenomena kultural yang mempunyai kaitan erat dengan musik hip hop.

\subsection{Teori Komunikasi Kritis}

Teori utama dalam karya ini adalah teori komunikasi kritis. Istilah teori kritis berasal dari kelompok ilmuwan Jerman yang dikenal dengan sebutan "Frankurt School". Menurut teori ini, komunikasi adalah refleksi penolakan terhadap wacana yang tidak adil. Dimana tugasnya adalah mengungkap kebeneran dalam penindasan yang terjadi di masyarakat dan memberikan perhatian yang sangat besar pada alat-alat komunikasi kepada masyarakat. Salah satu kendala komunikasi adalah bahasa yang digunakan oleh para individu itu sendiri. Karena, beberapa masyarakat masih menciptakan dan menggunakan suatu bahasa penindasan dan pengekangan. Jurgen Habermas mengatakan bahwa, "kewajiban dari teori kritis adalah menciptakan bentuk-bentuk bahasa baru yang memungkinkan diruntuhkannya paradigma dominan". Menurutnya, komunikasi sangat berpera penting bagi pembebasan. Karena bahasa adalah salah satu alat yang dapat mewujudkan kebebasan. (Primarni, 2010, h. 41).
Pada karya ini, pembuat karya akan membuat suatu acara yang membawa pesan kritik sosial yang terjadi di media sosial mengenai cyberbullying dengan komunikasi non-verbal. Dimana alat komunikasi, atau media komunikasi yang akan di gunakan adalah fashion. Setelah acara ini di laksanakan, diharapkan akan membuat para pengguna media sosial, khususnya para generasi muda Indonesia, agar menggunakan fasilitas media sosial dengan bijak dan benar. Dengan begitu, kasus-kasus yang sering terjadi di media sosial, seperti cyberbullying dan rasisme tidak akan terulang lagi.

\section{METODE PENELITIAN}

Karena naskah ini termasuk kedalam jenis merealisasikan konseptual sebuah naskah, maka metode yang digunakan dalam merealisasikan konsep acara ini adalah event management.

\subsection{Langkah- Langkah Karya}

Untuk mencapai tujuan dari acara yang akan dilaksanakan, perlu adanya beberapa strategi dan taktik agar acara yang akan dilaksanakan dapat berjalan dengan efektif. Yaitu :

1. Melaksanakan riset mencari informasi mengenai : kompetitor, contoh acara sebelumnya, masalah yang pernah timbul, peluang terhadap apa yang 
diselenggarakan, kelangsungan acara terhadap pasar.

2. Mengumpulkan informasi dan membuat data mengenai : tanggal penyelenggaraan, biaya dan sumber pemasukan, lokasi acara, tenaga kerja atau sumber daya manusia dan divisi pekerjaan setiap individu, target audience

3. Mengumpulkan informasi dan membuat data mengenai : anggaran, pemasukan, sponsor dan laporan keuangan.

4. Mengumpulkan informasi dan membuat data mengenai : Sumber daya, staff, lokasi, logistic, peralatan, jadwal pekerjaan, kesehatan, kesalamatan dan keamanan.

5. Menyiapkan acara mulai dari permasalahan teknis sampai keamanan.

6. Menyelenggarakan acara

7. Evaluasi Acara

\section{HASIL}

\subsection{PreEvent}

Dalam persiapan melaksanakan acara TRUCE, pembuat karya menyusun perencanaan dengan melengkapi beberapa data dan mengerjakan hal-hal yang perlu diselesaikan sampai pada hari pelaksanaan acara ini. Untuk merealisasikan acara TRUCE ini, memerlukan waktu kurang lebih 2 bulan untuk mempersiapkan acara. Tahap ini berlangsung dari awal bulan April 2017 hingga Mei 2017. Hal-hal yang dilakukan disaat sebelum acara berlangsung:

1. Pencarian sponsor, Pembuatan acara Fashion Show seperti ini membutuhkan dana untuk beberapa hal. Dalam hal ini, kami membutuhkan dana untuk venue, vendor, konsumsi, percetakan baju, biaya transportasi, guest star, dan lain-lain. Pembuatan acara seperti ini membutuhkan biaya yang besar untuk memenuhi beberapa kebutuhan acara. Dan juga membutuhkan tenaga suka relawan atau kami sebut dengan volunteer, agar acara dapat berjalan lancar sesuai dengan rencana. Agar acara ini dapat terwujud, maka dibutuhkan dukungan dari sponsor ataupun donatur. Melihat beberapa kebutuhan tersebut, kami selaku Mendata sponsor dan media yang menerima dan mendukung acara yang diselenggarakan. Yaitu : PT. Asaba, divisi Develop, PAC Martha Tilaar, Bee Flo, Coca Cola Indonesia, Kebun Kopi. Terdapat beberapa brand lokal yang mendukung acara dalam bidang wardrobe, yaitu : Dusky and Noble, Good Eyes, United Heart, Soze, Kaiga Jeans, Insurgent, Loony, MUZCA, United Hart. 
2. Pembuat karya melakukan survey ke beberapa tempat di Jakarta yang sesuai dan sepadan dengan tema pembuat karya yaitu Street Style. Contohnya adalah Galeri Salihara, Empirica Club dan The Foundry No.8.

3. Setelah melakukan survey ke tempat tersebut dan mempertimbangkan beberapa hal dalam pemilihan tempat acara, pembuat karya sepakat untuk mengadakan acara TRUCE di The Foundry No.8 SCBD, dikarenakan fasilitas yang memadai acara pembuat karya dan aksesbilitas yang lebih mudah di jangkau oleh para audience, dimana tempat tersebut juga sangat mendukung konsep street style yang sudah pembuat karya rencanakan.

4. Produser dan director, pembuat karya membuat proposal untuk disebarkan kepada para calon sponsor dan donatur. Tidak hanya itu, proposal juga dibagikan kepada beberapa media agar ada bantuan dalam mempublikasikan acara yang diselenggarakan.

Beberapa media berbasis online yang mendukung acara ini adalah : Sindhen, Event banget, Seputar Event, Ruang Media Art, Event Jakarta, Mazze Up, Provoke Magazine.
5. Pembuatan materi promosi acara. (poster, $e$ invitation, media pass, design layout untuk di media sosial)

6. Pembuatan media sosial resmi acara, yaitu Instagram.

7. Penyusunan serta pembagian divisi kerja panitia acara dan meeting panitia acara

8. Meeting panitia dan latihan, yang dilakukan selama tiga hari sebelum acara diselenggarakan

9. Gladiresik sebelum acara dimulai

\subsection{Main Event}

Acara TRUCE diawali dengan opening, dimana Natasha Rosanie, selaku main cast masuk ke dalam stage dan beracting sebagai korban cyberbullying untuk menjelaskan dampak dari perilaku cyberbullying, setelah itu ditayangkan video berdurasi kurang lebih 3 menit yang menjelaskan bahwa main cast tersebut adalah seorang vlogger. Lalu di lanjut dengan sequence pertama yang menjelaskan tentang kehidupan main cast sebelum di bully, saat suasana kehidupannya masih normal atau “senang”. Dimana di sequence ini, para model melakukan catwalk dengan berpakaian warnawarni beserta balon dan diiringi oleh salah satu rapper, yaitu Ben Utomo. Baju-baju yang dipertunjukkan adalah koleksi-koleksi dari Loony dan Dusky and Noble. 


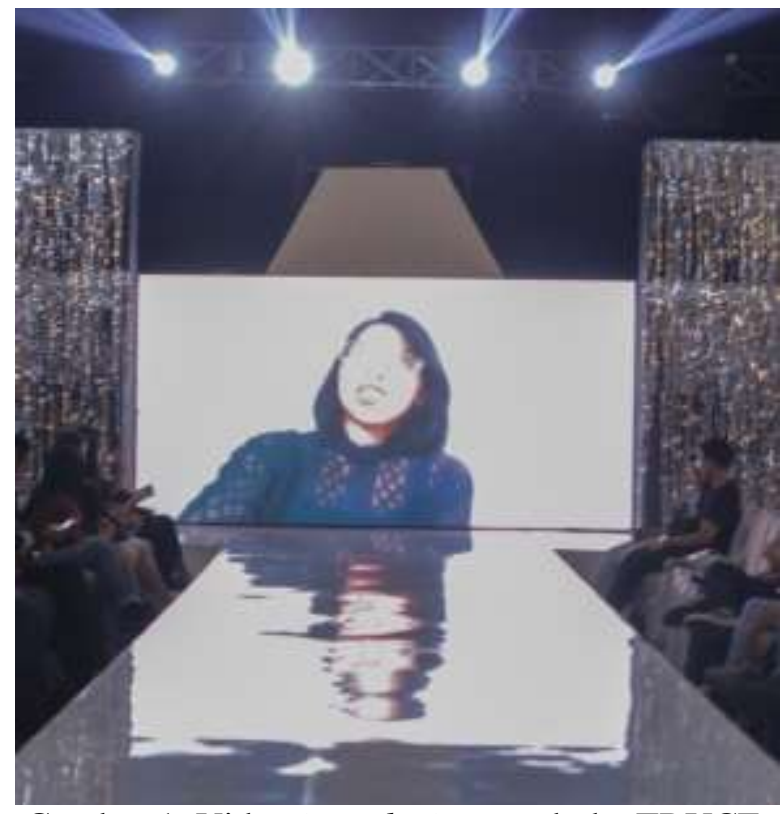

Gambar 1. Video introducing pembuka TRUCE, dari Marini, Firdaus, 2017

Di sequence kedua, main cast masuk keatas stage dan ber-akting, yang dilanjut dengan video berdurasi kurang lebih 3 menit, dimana di dalam video tersebut menjelaskan beberapa perilaku menyebalkan dari vlogger tersebut. Kemudian para model masuk stage dengan memakai baju dan bermimik wajah arogan untuk menjelaskan alasan dan penyebab korban dapat di bully, yang diiringi oleh salah satu rapper, yaitu Matter Mos. Baju-baju dan aksesoris yang di pertunjukan adalah koleksi-koleksi dari SOZE dan Good Eyes.

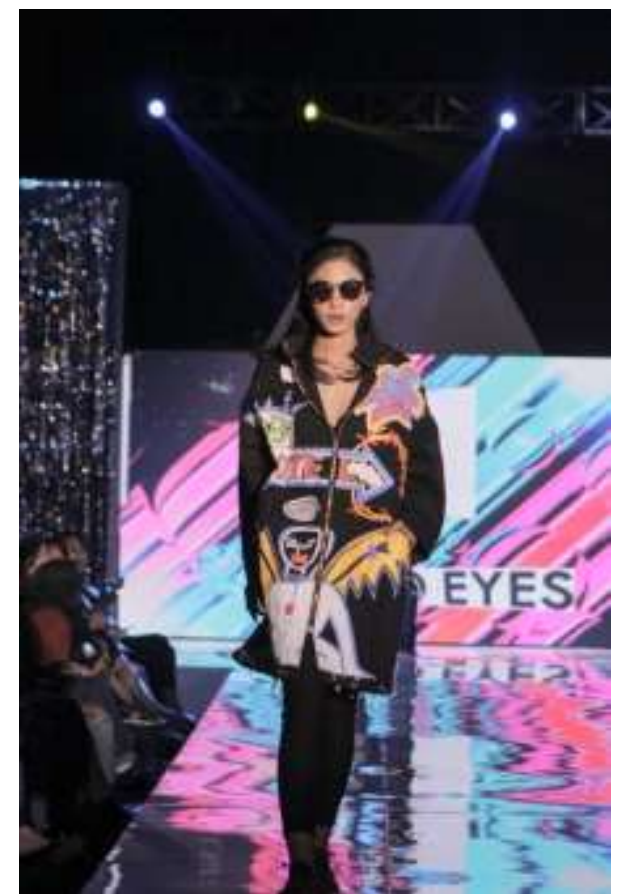

Gambar 2. Model menggunakan baju sesuai dengan alur cerita, dari Marini, Firdaus 2017

Di sequence ketiga, ditayangkan sebuah video berdurasi kurang lebih 3 menit yang menjelaskan bahwa publik sudah membicarakan tentang keburukan vlogger tersebut. Dilanjut oleh penampilan rapper, yaitu Gbrand dan ditemani oleh Matter Mos. Para model masuk ke dalam stage menggunakan beberapa pakaian glow in the dark yang bertulisan kata-kata hinaan untuk korban. Dari baju tersebut, para model menjelaskan alur bahwa publik sedang melakukan bullying terhadap korban dengan menggunakan kata-kata kurang baik. Outer yang di gunakan oleh para model pada sequence ini adalah koleksi-koleksi dari Muzca. 


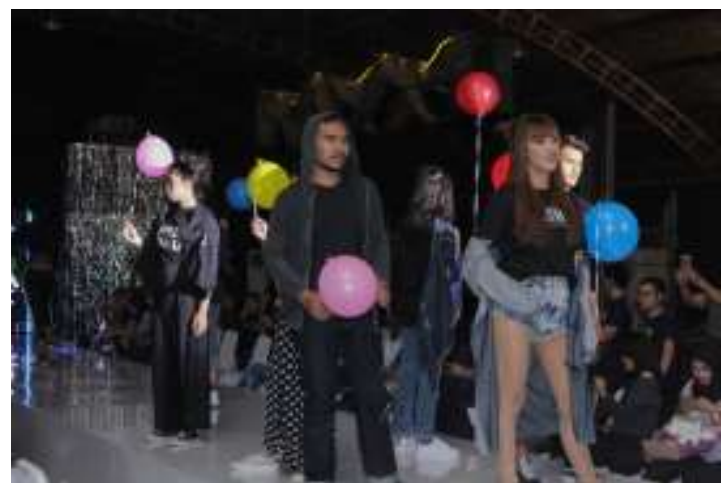

Gambar 3. Model menggunakan baju dengan bertuliskan kata-kata yang mewakili perilaku cyberbullying, dari Marini, Firdaus 2017

Dikarenakan terjadinya pergantian pakaian dari sequence 3 dan 4 yang sempat memakan waktu lebih lama, pembuat karya mengulur waktu dengan memberikan penampilan khusus yang menggabungkan 3 rapper, yaitu Ben Utomo, Gbrand dan Matter Mos. Setelah itu penampilan dari 3 penari dengan diiringi lagu yang berjudul U Mad dari Vic Mensa. 3 penari tersebut termasuk di dalam alur cerita TRUCE. Pada penampilan ini, para penari yang menggunakan pakaian serba hitam mengekspresikan emosi kemarahan, frustasi yang dialami oleh korban dari cyberbullying ini dan memberikan pesan dalam bentuk tarian dan juga lagu yang mengiringi tarian mereka, bahwa inilah perasaan yang dialami oleh cyberbullying saat sedang menghadapi serangan-serangan dari para pelaku cyberbully di Internet.

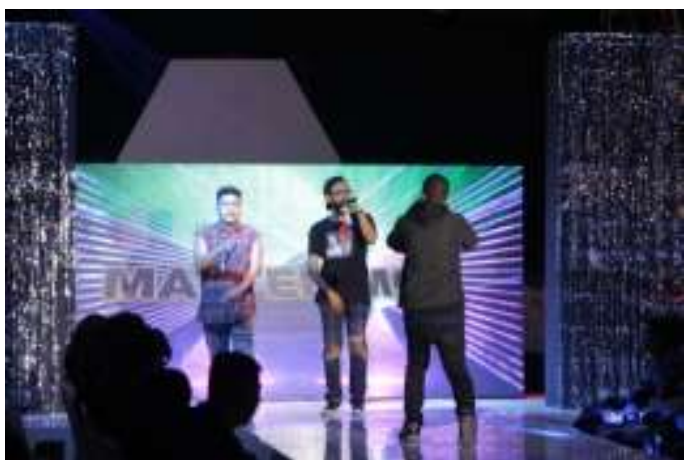

Gambar 4. Penampilan tiga guest star, dari Marini, Firdaus 2017

Kemudian, model masuk stage dengan menggunakan baju berwarna hitam bertema dark. Di sequence ini para model menjelaskan perasaan dari korban setelah di bully. Pakaian dan aksesoris yang digunakan adalah koleksikoleksi dari UH, Insurgent dan Kaiga Jeans. Dilanjut dengan masuknya main cast ke dalam stage dan beracting seperti orang yang memiliki tekanan tinggi terhadap suatu keadaan. Dimana di sequence 4 ini menjelaskan tentang salah satu contoh dampak yang diperoleh dari korban cyberbullying. 


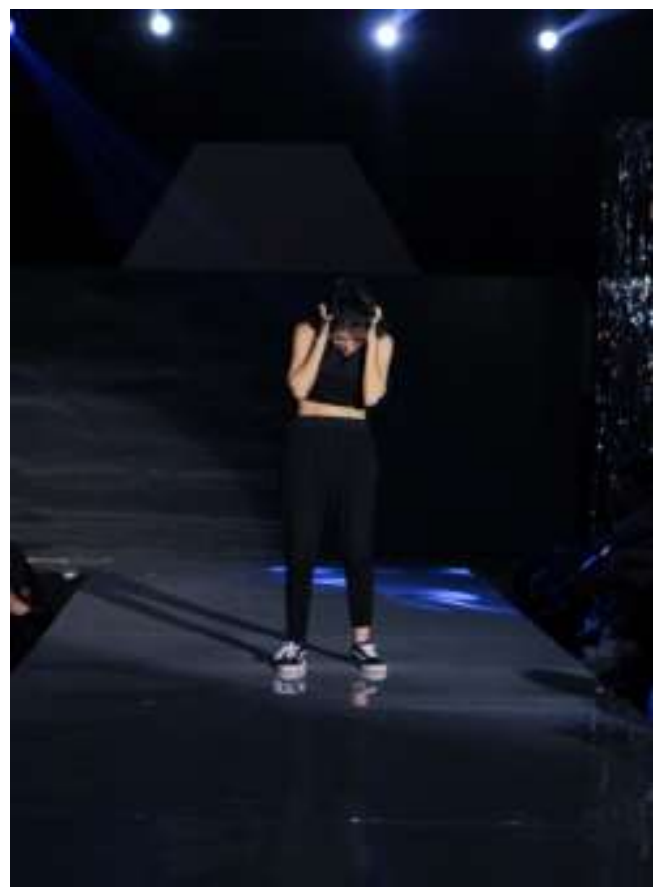

Gambar 5. Teatrikal dari aktor, dari Marini,

Firdaus 2017

Rangkaian acara TRUCE di akhiri dengan masuknya para model dengan membawa hand properties yaitu papan yang bertuliskan pesan-pesan tentang ajakan untuk berhenti melakukan cyberbullying. Pakaian yang digunakan adalah koleksi-koleksi dari UNITED HART dan Insurgent. Diakhir acara, seluruh model masuk kembali ke panggung dan melakukan ending pose. Kemudian, Production Manager dan Director dari acara TRUCE, naik ke atas panggung untuk memberi hormat dan rasa terima kasih kepada para tamu undangan dengan ditemani salah satu Social Media Influencer / Public Figure yang juga sekaligus main model TRUCE, yaitu Laras Syerinita yang membawakan rangkaian bunga untuk diberikan kepada Ratih dan Veby.

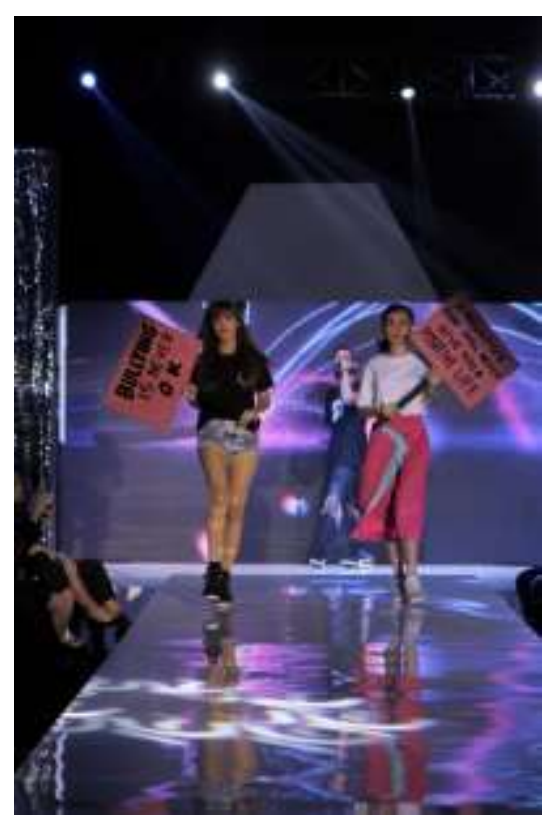

Gambar 6. Model membawa 2 papan anti cyberbullying, dari Marini, Firdaus, 2017

\section{KESIMPULAN}

Acara "TRUCE: The True Elucidation of Cyberbullying" yang telah dilaksanakan pada hari Rabu, tanggal 24 Mei 2017 telah berhasil mendapat respon yang positif dari masyarakat, hal itu menunjukkan keberhasilan dari acara TRUCE dengan tercapainya tujuan karya dari pembuat karya.

Setelah selesai berjalannya acara TRUCE, para tamu undangan dapat menerima dengan baik pesan yang pembuat karya telah sampaikan, yaitu untuk tidak melakukan cyberbullying. Hal ini dapat dibuktikan dari beberapa comment dan postingan positif dari beberapa tamu undangan dan juga hasil 
kuesioner yang telah dibagikan. Kuesioner yang dibagikan sebanyak 100 lembar dan yang terkumpul kembali sebanyak 50 lembar. Dari bukti-bukti tersebut dapat membuktikan bahwa pertunjukan fashion show yang dikolaborasikan dengan teater dan musik juga dapat menyampaikan pesan dengan baik.

Harapan pembuat karya, TRUCE dapat menjadi pioneer dan awal dari acara-acara serupa. Pembuat karya juga berharap TRUCE dapat menjadi acara yang menginspirasi banyak orang untuk membuat acara yang serupa yang tidak hanya mempunyai sisi hiburan tapi ada pesan positif yang disampaikan kepada audience.

\section{DAFTAR PUSTAKA}

Akbar, Utari (2015, h.2). Komunikasi. Cyberbullying Pada Media Sosial Diperoleh dari http://www.jurnalkommas.com/docs/J URNAL\%20-\%20FIX.pdf

Aranditio (2014). Stop Cyberbullying Diperoleh dari http://arsippublik.blogspot.co.id/2014/ 09/stop-cyberbullying.html

Bambaataa (2005). Hip-Hop Perlawanan dari Ghetto, Yogyakarta: Alinea

Barnard, M. (1995). Fashion sebagai Komunikasi, Bandung: Jalasutra

Eaten, G. (2014). wear no evil : how to change the world with yourwardrobe. New York: Perseus Books Group

Kumparanstyle (2017). 41 Persen Remaja Indonesia Pernah Alami Cyberbullying
Diperoleh dari https://kumparan.com/@kumparanstyl e/41-persen-remaja-indonesia-pernahalami-cyberbullying

Kowalski, R.M., Limber, S.P., Agatston, P.W. (2008). Cyber Bullying: Bullying in the Digital Age. United States of America: BlackwellPublishing.

Lukman, E. (2014). 30 Juta pengguna internet di Indonesia adalah remaja. Diperoleh dari https://id.techinasia.com/laporan30-juta-pengguna-internet-diindonesia-adalah-remaja

MacEachern, R. and Charrete, G. (2010). Cyberbullying: Deal with it and Ctrl Alt Delete it Deal With It. Ontario: James Lorimer \& amp Company.

Mamduh, M. (2015) 30 Juta Aanak Muda Pengguna Aktif Sosial Media Diperoleh dari http://teknologi.metrotvnews.com/read /2015/12/22/203805/30-juta-anakmuda-pengguna-aktif-sosial-media

Primarni, A. (2010). Pengantar Ilmu Komunikasi : Memahami Dasar Komunikasi. Jakarta: Lentera Ilmu Cendekia

Putra, D.F. (n.d) "Ketika Bullying Berujung Maut". Diperoleh dari website CNNIndonesia:

http://www.cnnindonesia.com/gayahidup/20140910112008-2552906/ketika-bullying-berujung-maut/

Ruslan, R. (2008). Kiat dan Strategi Kampanye Public Relations. Jakarta: Rajagrafindo.

Sasyachi. (2014).Street Style Quick Tips Diperoleh dari website: http://www.hellosasyachi.com/2014/06 /street-style-quick-tips.html 
Spivet, B. (2011). Stopping Cyberbullying, The Rosen Publishing Group, New York.

Staff. (2014, June 20). "Michael Waters : Hip Hop is Communication" Diperoleh dari

http://www.waccglobal.org/articles/mi chael-waters-hip-hop-iscommunication
Wood, J. (2016, July 22). Marie Claire : The best fashion blog ever. Diperoleh dari http://www.marieclaire.co.uk/fashion/t he-best-fashion-blogs-ever-69888

https://kumparan.com/@kumparanstyle/41persen-remaja-indonesia-pernah-alamicyberbullying 